\title{
MICROSTRUCTURAL CHARACTERIZATION OF PM 625-TYPE MATERIALS
}

\author{
Frank J. Rizzo and Dr. John Radavich \\ Crucible Compaction Metals \\ McKee and Robb Hill Roads \\ Oakdale, Pennsylvania 15071 \\ and \\ Purdue University \\ West Lafayette, Indiana 47906
}

\begin{abstract}
Crucible has been a pioneer in manufacturing PM 625-type materials for applications where good corrosion resistance and medium to high strength characteristics are a necessity. A unique feature of the PM version of these type of materials is the ability to control strengthening by conventional heat treatment cycles. There are some microstructural responses in the alloy which help explain the properties. A microstructural study of the powder before and after consolidation sheds some light on what is happening during the processing of these alloys.
\end{abstract}

\section{Introduction}

During the past ten years, companies working in the $0 i 1$ and Gas Industry have been looking for good corrosion resistant alloys for a wide variety of applications in services where sour environments are prevalent. Tradition-ally, the alloys of choice for these applications have been C-276 for tubulars and alloy 718 for forged and/or rolled shaped parts. C-276 must be used in the cold worked condition to get the required strength levels for oil or gas well use. This limits its applicability primarily to tubulars although recent work has been focused on cold worked C-276 billet material. Alloy 718 can be made in standard mill product forms as well as forged shapes and can be heat treated to reach the desired strength levels. It is usually used in the partially overaged condition to get better corrosion resistance. In spite of this, it still has a temperature limitation for good stress corrosion resistance. Most of the new wells cannot use alloy 718 for this reason. Conventional wrought alloy 625 has always been an attractive material because it has corrosion resistance between C-276 and a1loy 718 . However, wrought alloy 625 exhibits non-reproducible hardening response during heat treatment and hardening by cold working is apparently too difficult and can adversely effect the corrosion resistance.

The powder metal version of alloy 625 has been shown to achieve a measure of precipitation hardening with conventional solution treat and age heat treatments. This has been demonstrated for product forms such as solid nearnet shapes, mill forms and clad products. Even with the higher strength levels associated with the age hardening of this alloy, the stress corrosion resistance remains good and makes it the leading candidate for the critical parts in sour environment service.

Superalloys 718,625 and Various Derivatives Edited by Edward A. Loria

The Minerals, Metals \& Materials Society, 1991 


\section{Background}

While the powder metal version of alloy 625 is nominally the same composition as the conventional material, it exhibits different age hardening responses'. PM 625 is a rapid solidification product with chemical homogeneity and a fine grained microstructure. This partially explains why this product can be readily heat treated and conventional material generally cannot. Over the years there has been considerable work done with wrought alloy 625 to establish the phase relationships ${ }^{2}$ and its corrosion characteristics ${ }^{3}$. These do not necessarily apply to PM 625 especially since it is used in the fully heat treated condition versus the annealed condition for conventional material.

As with any material, there are variations in mechanical properties from time to time. PM 625 is no exception. This study has been carried out to gain some insight into the physical metallurgy of this alloy to help yield a more consistent product. PM 625 is manufactured differently than conventional wrought 625 ; there is a need to look at the material processing sequence to see which steps have to be tightly controlled to achieve the desired product results.

\section{Powder}

Powder is made by vacuum induction melting a combination of virgin raw materials and revert (i.e., oversized powder) from previous powder blends. The furnace charge for a single heat is nominally $2272 \mathrm{~kg}$ (5000 lbs). Once liquid, the metal is poured through a small diameter refractory nozzle to form a fine stream which is impinged upon by a high velocity of argon gas. As the stream breaks up, the metal solidifies as spheres and cools as it falls into the collection tower. Some of the fine particles are carried off with the exhaust gasses and are collected in an attached cyclone separator and are recombined with the other powder before processing.

The powder is screened to yield a maximum particle size of 150 microns and then a number of heats are combined to make a master powder blend. Chemistries of typical blends of PM 625 appear in Table I. These blends represent thousands of pounds of powder made in several melt campaigns over the past few years. There are only a few subtle variations in the compositions for all the material. The carbon level varies from 0.015 to 0.026 percent, the oxygen from $70 \mathrm{ppm}$ to $120 \mathrm{ppm}$, and the iron from 1.05 to 1.41 percent. All other elements show no significant differences. As with most alloys, a balance of the chemistry is important to attaining good reproducible properties.

During powder processing, it is possible to pick up oxygen on the surface of the particles. Proper handling is necessary to keep the oxygen content to a minimum. Powder is considered highly homogeneous from particle to particle because it is formed from an induction melted liquid and solidifies rapidly. Each particle essentially has the composition of the liquid. With conventional ingot metallurgy material, alloy 625 is made as a highly segregated ingot and must be hot worked to standard mill forms to break down the segregated microstructure to get a useable product. Any number of deleterious phases can form because of the elemental segregation and these can only be removed by extensive thermo-mechanical processing.

Figure 1 shows SEM micrographs of 625 powder from Blend $F$. It is typical of gas atomized powders. The particles are spherical or near spherical and there is some satelliting of small particles. The surface shows no evidence of film formation or discrete particle precipitation. At high magnifications there are some very small particles visible. They have smooth surfaces and appear to be imbedded in the crevices of the larger particles. These small particles have been analyzed on the SEM as the nominal 625 composition. 
Table I PM 625 Blend Chemistries

\begin{tabular}{|c|c|c|c|c|c|c|c|}
\hline Weight Percent & & & & Blend & & & \\
\hline for: & A & B & C & D & $\mathrm{E}$ & $\mathrm{F}$ & G \\
\hline $\begin{array}{l}\mathrm{C} \\
0 \\
\mathrm{~N}\end{array}$ & $\begin{array}{l}0.015 \\
0.012 \\
0.005\end{array}$ & $\begin{array}{l}0.017 \\
0.011 \\
0.005\end{array}$ & $\begin{array}{l}0.026 \\
0.009 \\
0.005\end{array}$ & $\begin{array}{l}0.021 \\
0.009 \\
0.006\end{array}$ & $\begin{array}{l}0.020 \\
0.009 \\
0.007\end{array}$ & $\begin{array}{l}0.016 \\
0.010 \\
0.006\end{array}$ & $\begin{array}{l}0.019 \\
0.007 \\
0.006\end{array}$ \\
\hline $\begin{array}{l}\text { Cr } \\
\text { Mo }\end{array}$ & $\begin{array}{r}20.95 \\
8.87\end{array}$ & $\begin{array}{r}20.86 \\
8.56\end{array}$ & $\begin{array}{r}21.28 \\
8.97\end{array}$ & $\begin{array}{r}21.43 \\
8.88\end{array}$ & $\begin{array}{r}21.56 \\
8.92\end{array}$ & $\begin{array}{r}21.45 \\
8.89\end{array}$ & $\begin{array}{r}21.49 \\
8.88\end{array}$ \\
\hline $\begin{array}{l}\mathrm{Cb} \\
\mathrm{Ti} \\
\mathrm{Al}\end{array}$ & $\begin{array}{l}3.87 \\
0.22 \\
0.22\end{array}$ & $\begin{array}{l}3.87 \\
0.22 \\
0.27\end{array}$ & $\begin{array}{l}3.79 \\
0.27 \\
0.28\end{array}$ & $\begin{array}{l}3.77 \\
0.26 \\
0.25\end{array}$ & $\begin{array}{l}3.77 \\
0.26 \\
0.28\end{array}$ & $\begin{array}{l}3.77 \\
0.26 \\
0.25\end{array}$ & $\begin{array}{l}3.77 \\
0.26 \\
0.32\end{array}$ \\
\hline $\begin{array}{l}S \\
S i \\
M n \\
P\end{array}$ & $\begin{array}{l}0.001 \\
0.08 \\
0.04 \\
0.010\end{array}$ & $\begin{array}{l}0.002 \\
0.08 \\
0.03 \\
0.009\end{array}$ & $\begin{array}{l}0.001 \\
0.07 \\
0.03 \\
0.009\end{array}$ & $\begin{array}{l}0.001 \\
0.05 \\
0.03 \\
0.009\end{array}$ & $\begin{array}{l}0.001 \\
0.05 \\
0.05 \\
0.008\end{array}$ & $\begin{array}{l}0.002 \\
0.06 \\
0.05 \\
0.010\end{array}$ & $\begin{array}{l}0.003 \\
0.07 \\
0.04 \\
0.008\end{array}$ \\
\hline $\begin{array}{l}\mathrm{Fe} \\
\mathrm{Ni}\end{array}$ & $\begin{array}{r}1.05 \\
62.60\end{array}$ & $\begin{array}{r}1.10 \\
62.54\end{array}$ & $\begin{array}{r}1.41 \\
61.67\end{array}$ & $\begin{array}{r}1.28 \\
62.00\end{array}$ & $\begin{array}{r}1.41 \\
61.70\end{array}$ & $\begin{array}{r}1.41 \\
61.80\end{array}$ & $\begin{array}{r}1.41 \\
62.00\end{array}$ \\
\hline
\end{tabular}

Table II Room Temperature Tensile Properties of Blend C Material

\begin{tabular}{|c|c|c|c|c|c|}
\hline $\begin{array}{l}\text { Specimen } \\
\text { Code }\end{array}$ & Solution Treatment & $\begin{array}{c}\text { UTS } \\
\mathrm{MPa}(\mathrm{ksi})\end{array}$ & $\begin{array}{l}0.2 \% \mathrm{YS} \\
\mathrm{MPa}(\mathrm{ksi})\end{array}$ & $\begin{array}{l}E 1 \\
\%\end{array}$ & $\begin{array}{l}\text { RA } \\
\%\end{array}$ \\
\hline$C-1$ & $927 \mathrm{C}(1700 \mathrm{~F}) / 1 \mathrm{hr} / \mathrm{WQ}$ & $933(135.3)$ & $501(72.6)$ & 44.3 & 41.8 \\
\hline$C-2$ & $982 \mathrm{C}(1800 \mathrm{~F}) / 1 \mathrm{hr} / \mathrm{WQ}$ & $931(135.0)$ & $488(70.8)$ & 46.8 & 54.5 \\
\hline $\begin{array}{l}C-3 \\
C-4\end{array}$ & $1038 \mathrm{C} \underset{"}{(1900 \mathrm{~F})} / 1 \mathrm{hr} / \mathrm{WQ}$ & $\begin{array}{ll}929 & (134.7) \\
927 & (134.5)\end{array}$ & $\begin{array}{l}490(71.0) \\
499(72.4)\end{array}$ & $\begin{array}{l}47.5 \\
37.0\end{array}$ & $\begin{array}{l}54.0 \\
28.6\end{array}$ \\
\hline$C-5$ & $1093 \mathrm{C}(2000 \mathrm{~F}) / 1 \mathrm{hr} / \mathrm{WQ}$ & $926(134.3)$ & $514(74.6)$ & 43.9 & 47.9 \\
\hline$C-6$ & $1149 \mathrm{C}(2100 \mathrm{~F}) / 1 \mathrm{hr} / \mathrm{WQ}$ & $926(134.3)$ & $513(74.4)$ & 44.1 & 39.4 \\
\hline
\end{tabular}



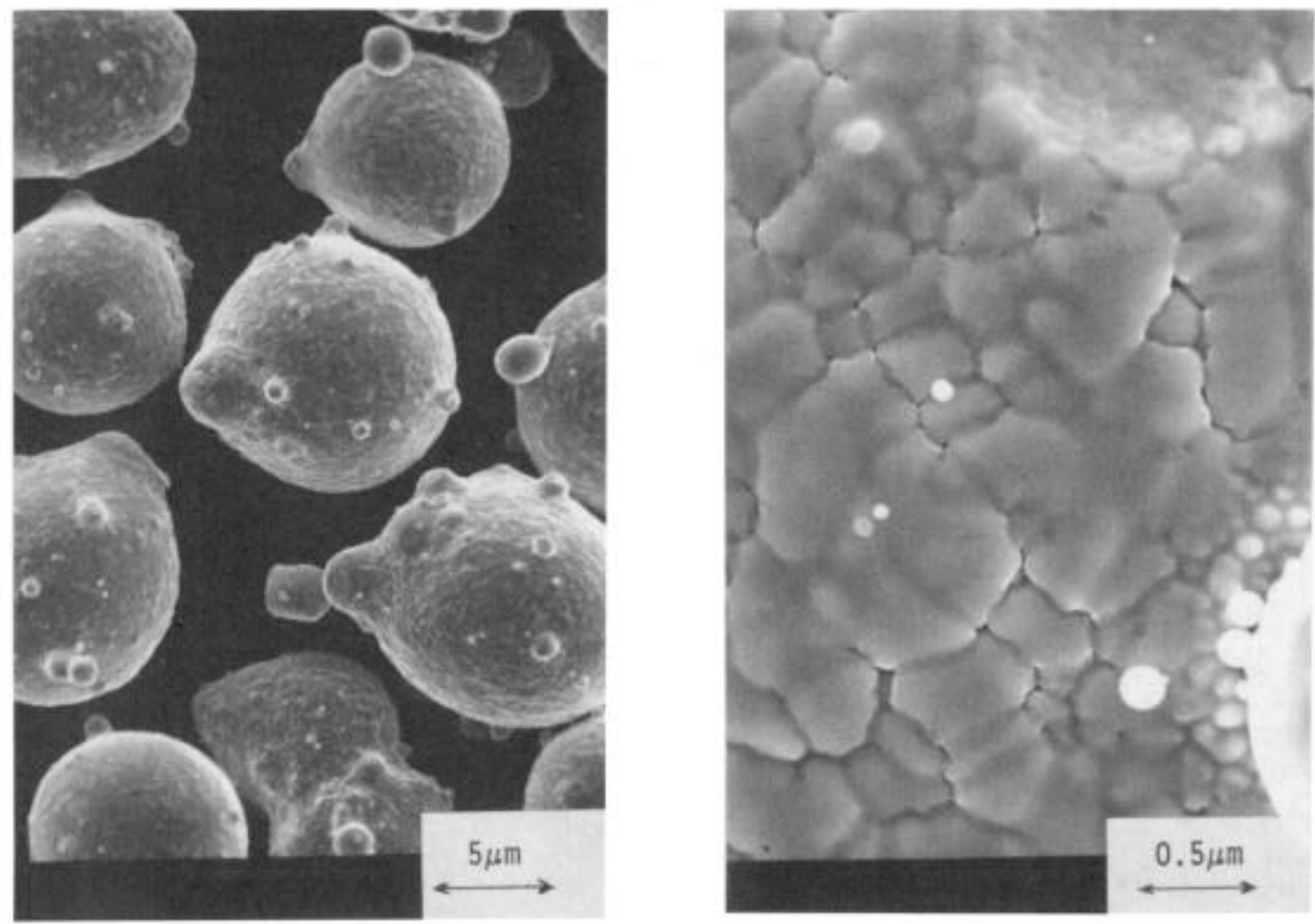

Figure 1 - SEM Micrographs of PM 625 Powder of Blend F

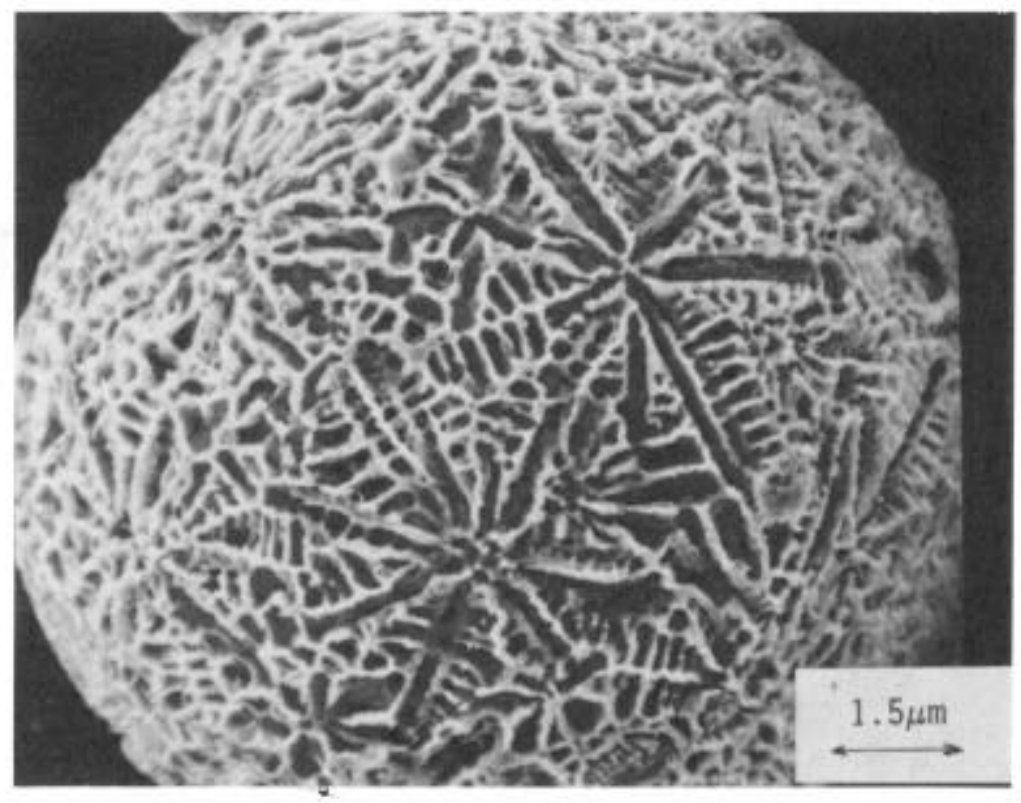

Figure 2 - SEM Micrograph of a Blend F Powder Particle After Electrolytic Extraction 
An electrolytic extraction was conducted on loose powder from Blends $C$ and $F$. Both showed the same results. Figure 2 shows a SEM micrograph of a particle after the extraction procedure. The interdendritic regions are dissolved away and a network of dendrites remains. X-ray diffraction analyses of the extracted residues revealed three different sizes of constituents. The large material primarily contained matrix and a slight indication of a Laves-type phase. The medium and fine residues al so contained matrix, to a lesser extent, the Laves-type phase and a small amount of MC carbide. Blend $C$ exhibited a little less MC carbide than Blend F. Some of the very fine alloy 625 particles were extracted along with the interdendritic material and they were unaffected by the acids.

Cross-sectional metallographic analyses of the same powders indicated that the same type of interdendritic phases appear throughout the powder particles. Figure 3 shows SEM micrographs of a powder cross section from Blend $\mathrm{C}$ powder. The Laves-type phase present in these powders is a $(\mathrm{Ni}, \mathrm{Cr})_{2}(\mathrm{Mo}, \mathrm{Nb})$ phase whose chemistry is approximately $50.83 \% \mathrm{Ni}, 17.49 \% \mathrm{Cr}, 14.43 \% \mathrm{Mo}, 16.62 \% \mathrm{Nb}$, and $0.63 \% \mathrm{Ti}$. This would indicate that there is a micro-segregation of these elements in the interdendritic regions of the powder form of this alloy. The only other phases present in the powders is matrix and a small amount of fine MC carbides which are predominantiy $(\mathrm{Nb}, \mathrm{Ti}) \mathrm{C}$ based on the lattice parameter of $4.387 \AA$.

\section{Consolidated Product}

The final step of powder processing is the consolidation to a fully dense product. This is most commonly accomplished by hot isostatic pressing (HIP) although extrusion has also proven to be an effective method to obtain full densification. The chemistry of the material can be altered during this step in the processing. The powder container and the powder in it must be properly evacuated to remove the atmosphere in the space around the tightly packed powder and any adsorbed gasses from the powder or the container walls. If the container is not crimped properly, it can leak back air inside and the oxygen and nitrogen content of the compact can be effected. If there is a problem with weld or stem crimp integrity during the HIP cycle densification (i.e., shrinkage) the container will fill or partially fill with the autoclave pressurizing gas (i.e., argon) and later result in a non-fully dense compact or one with high thermally induced porosity (TIP) which is a density decrease associated with subsequent thermal cycling of the part.

The effect of high TIP on mechanical properties is not completely known. However, it can result in a porous microstructure depending on subsequent thermal cycles and this is normally not conducive to good long time properties such as creep or fatigue. The effect of an air leak on the microstructure and resultant mechanical properties is dramatic. A compact made of Blend $F$ with no outgassing at a11 (i.e., a worst case scenario) was HIP and a SEM micrograph of the structure is shown in Figure 4 . There is considerable prior particle boundary precipitation which is $\mathrm{Al}-\mathrm{rich}$ and is probably $\mathrm{Al}_{2} \mathrm{O}_{3}$. There are areas of continuous film on particle boundaries and large areas of interparticle precipitates. Figure 5 shows SEM micrographs of a fracture surface from the same compact and there are obvious signs of low ductility and some powder particles have the same surface appearance as the loose powder shown in Figure 2. This would indicate a lack of effective bonding which has been caused by the oxide film formation on particle boundaries. 

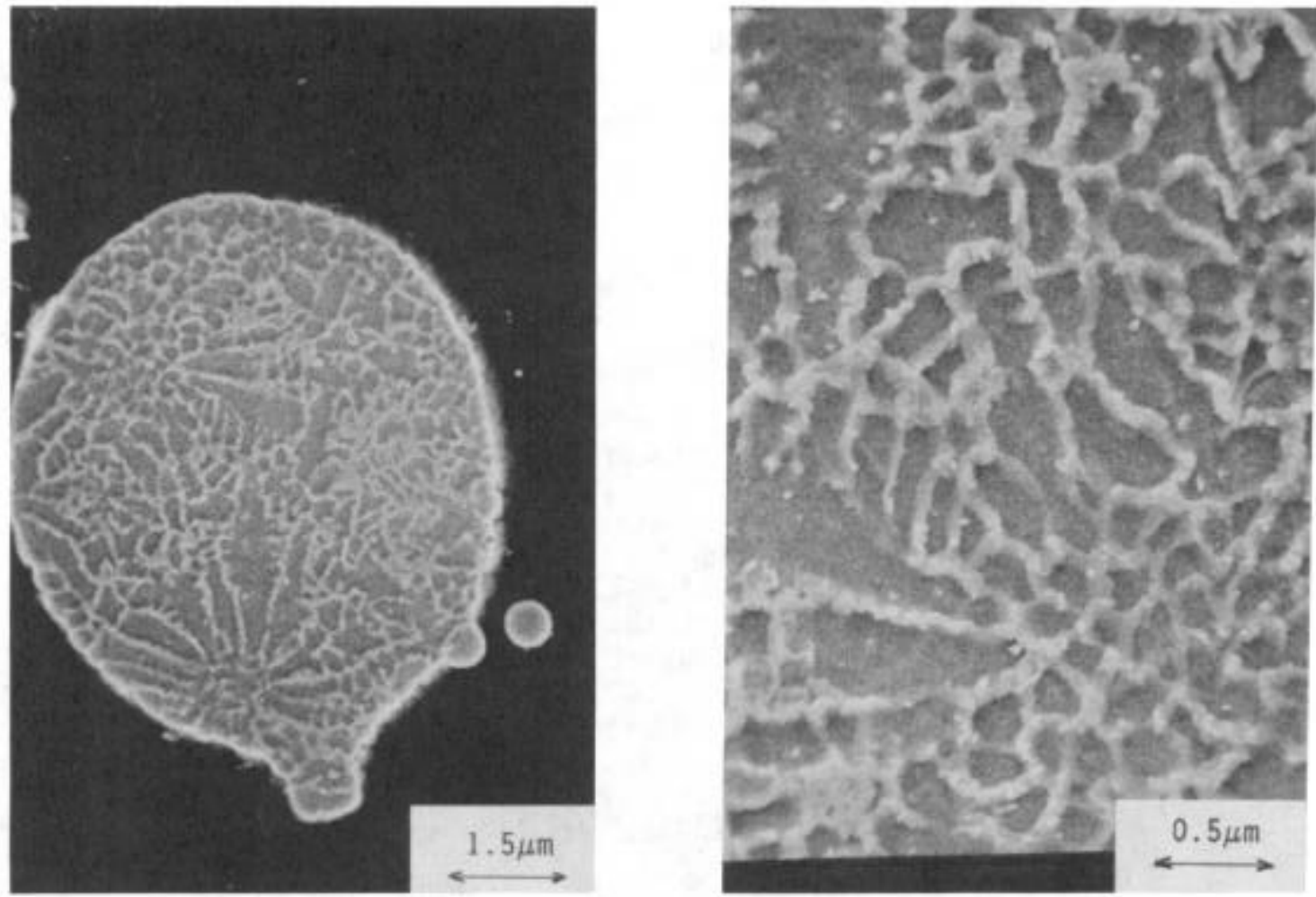

Figure 3 - SEM Micrograph of a Cross-Section of Blend C Powder After Electrolytic Extraction

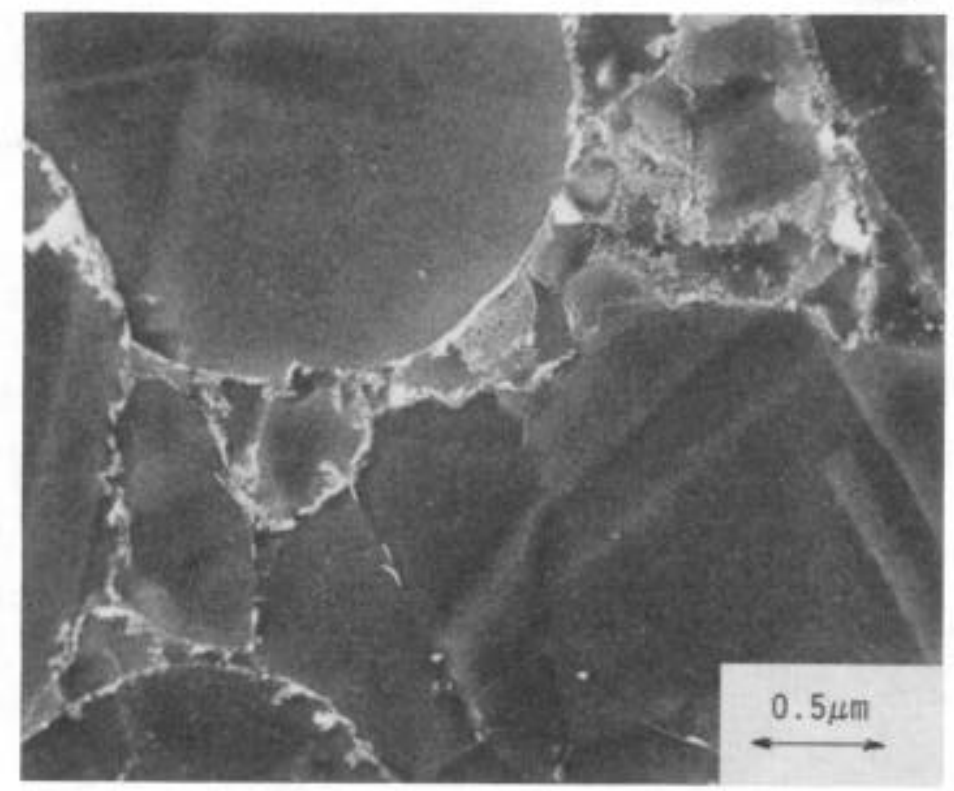

Figure 4 - SEM Micrograph of as-HIP Blend F Powder Consolidated Without Outgassing 

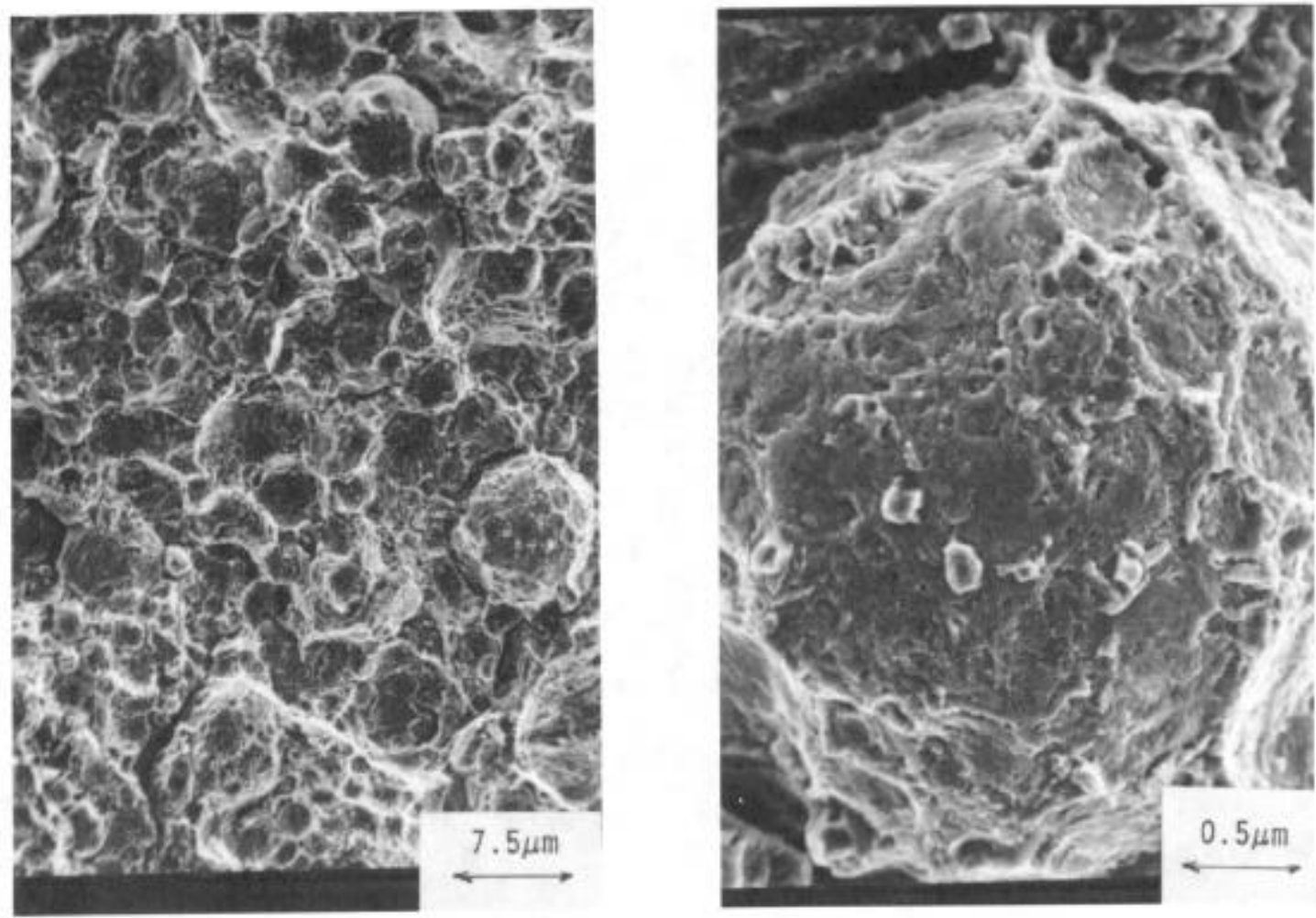

Figure 5 - SEM Micrograph of A Fracture Surface of Blend F Powder Consolidated Without Outgassing

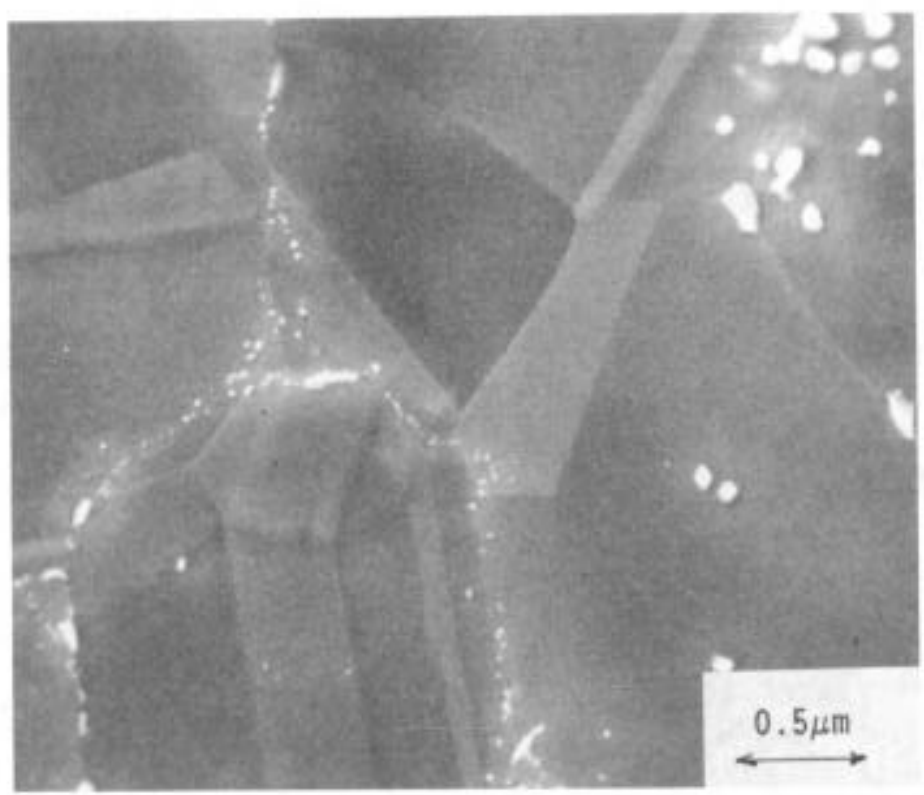

Figure 6 - SEM Micrograph of as-HIP Blend A Powder Processed Properly 
Figure 6 shows a SEM micrograph of the as-HIP structure of a properly outgassed and consolidated compact of Blend A powder. It indicates that there is a discrete precipitate on the particle boundaries. This precipitate was identified as MC carbide with a lattice parameter of 4.44 A which indicates a $\mathrm{NbC}$. There are large MC carbides as well as small MC carbides which probably means the large precipitate formed during the HIP cycle. There is also a slight indication of very fine Al-rich oxides as seen by particle florescence on the SEM. These also formed during the consolidation process because there was no indication of them in the powder. The small MC carbides were the only precipitated phase present in the loose powder. Since the grain structure has grown through the particle boundaries, the presence of these carbides and oxides does not hinder good bonding. A fracture surface of this material shows good ductility and no evidence of a bonding problem.

Consolidated material from each of the other blends listed in Table I was examined and found to have the same type of microstructure described above. The compact investigated from Blend $C$ was slightly different in that in addition to the MC carbides at particle boundaries, it also exhibited Mo-rich $M_{6} C$ carbides. This blend has the highest carbon content of all those listed and this may be the reason for the formation of $M_{6} C$ along with the $M C$. No Laves-type phase was found in any of the consolidated product from any blend. During the HIP process, the Laves-type phase apparently solutions and the $\mathrm{Nb}$ combines with $C$ to form the large MC carbides and the Mo combines with $C$ to form the $M_{6} C$ carbides shown in Blend $C$. The effect of the $M_{6} C$ precipitates will be discussed below.

\section{Solution Heat Treatment}

The initial thermal treatment for conventional wrought 625 is a solution heat treatment which has traditionally been in the range from $927 \mathrm{C}$ (1700F) to $1204 \mathrm{C}$ (2200F) for the purpose of solutioning the phases that form during the manufacturing of the product. As shown above, with PM 625 the only phases present in the as-HIP product are matrix, $M C$ and, in one case, $M_{6} C$ carbides.

Blend A material was given solution treatments ranging from $927 \mathrm{C}$ (1700F) to $1260 \mathrm{C}$ (2300F) for one hour at temperature. Figure 7 shows a SEM micrograph of the sample exposed at $1260 \mathrm{C}$ (2300F). The large MC carbides have for the most part gone into solution and some precipitates have been polished or etched out to leave voids. The second phases still present are the small MC carbides, which were present in the powder, and the very fine Al-rich oxides. All of the samples with temperature exposures up to $1260 \mathrm{C}$ (2300F) show that the large MC precipitates are progressively going into solution.

The $B$ lend $C$ material showed a similar trend with increasing solution treatment temperature. The large MC carbides progressively go into solution leaving only the small $M C$ carbides and the Al-rich oxides in the microstructure. The $M_{6} C$ carbides, however, go into solution around $1093 \mathrm{C}(2000 \mathrm{~F})$. Some room temperature tensile data was generated on the Blend $C$ samples to determine the effect on the strength and ductility of the material. Table II lists this information. As the solution temperature increases, the strength shows a slight trend to increase. The ductility, measured primarily by the reduction of area, increases to $1038 \mathrm{C}$ (1900F) and then decreases as the solution temperature increases to $1149 \mathrm{C}(2100 \mathrm{~F})$. A duplicate test at $1038 \mathrm{C}$ (1900F) shows a much lower ductility than the original test. Microstructural work on these two specimens indicated that $C-3$ contained much higher ratio of $M C / M_{6} C$ than specimen $\mathrm{C}-4$. The presence of the $M_{6} C$ carbide seems to lead to wide variability in ductility. Specimens $C-5$ and $C-6$ show decreasing ductility and 


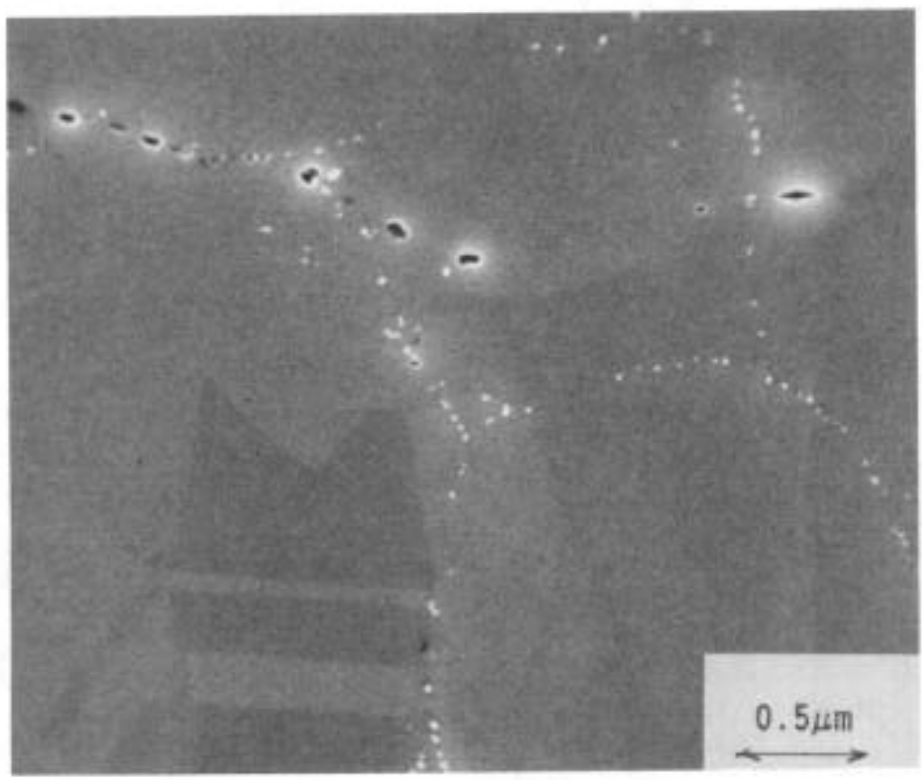

Figure 7 - SEM Micrograph of HIPed Blend A Powder Solution Treated at $1260 \mathrm{C}$ (2300F)

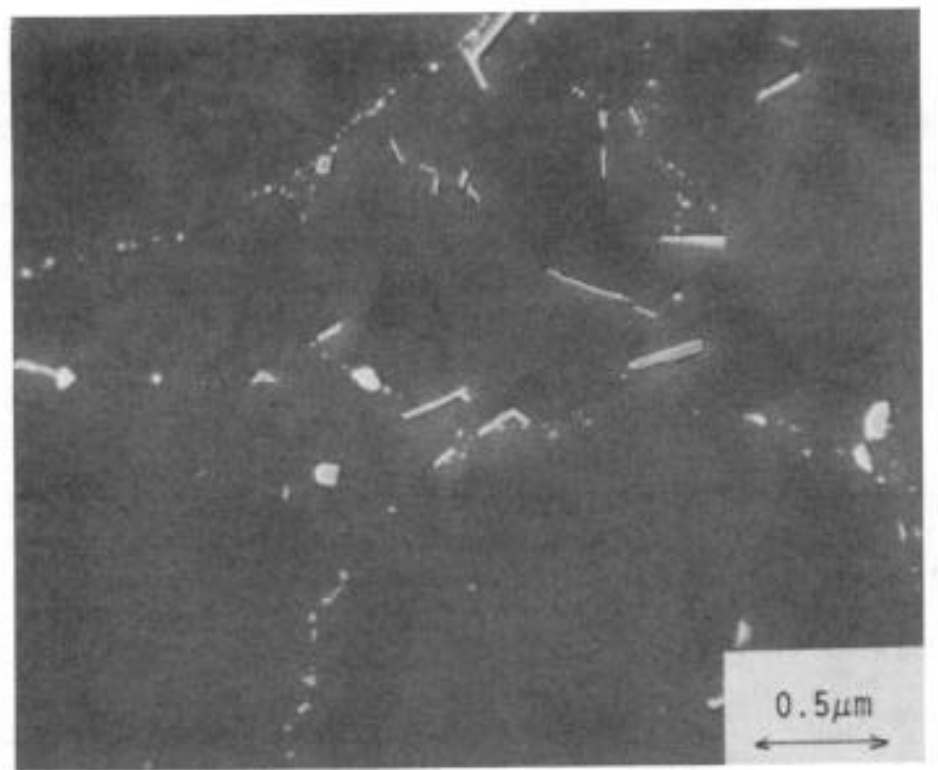

Figure 8 - SEM Micrograph of Blend G Powder After a $871 \mathrm{C}$ (1600F)/10 Hour Treatment 
there was no $M_{6} C$ detected in either one. However, large $M C$ precipitates are being solutioned and this may explain the decreasing ductility trend shown in Table II.

It appears that the presence of large and small MC carbide precipitates are important to good strength and ductility and the presence of $M_{0} C$ carbides leads to erratic ductility without effecting strength for PM 625. One method to help control the carbide distribution is to keep the carbon level in the alloy on the low side. Corrosion resistance should also benefit from the lack of $M_{6} C$ precipitation because the matrix will be richer in Mo.

\section{Precipitation Hardening Treatment}

Table III contains room temperature tensile data generated on the PM 625 powder blends. By comparison to the data on some of the same material in the solution treated condition (i.e., Table II), it appears that age hardening occurs in as little as four hours at temperatures as 1ow as 593C (1100F). Longer times and higher temperatures result in higher strengths and for the most part lower ductilities. As in the case of the solution treated material, the aged material also shows some variation in reduction of area.

As shown above, the solution treatments given to the fully heat treated material should have little or no effect on the phases present prior to aging. Thus, all the specimens from all of the blends contain large and small MC carbides which will vary only slightly from blend to blend and with the differences in solutioning temperature. Blend $C$ material should also contain some $M_{6} C$. The aging treatments were expected to result in the precipitation of gamma prime (Ni, $\mathrm{Al})$, gamma double prime $\left(\mathrm{Ni}_{3} \mathrm{Cb}, \mathrm{Al}\right)$, and/or delta $\left(\mathrm{Ni}_{3} \mathrm{Cb}\right)$ phase. Metallographic and phase extraction work indicated that this is not the case for PM 625. No gamma prime or delta phase was found. However, gamma double prime was detected after aging for times at least as long as 16 hours at $677 \mathrm{C}$ (1250F) or higher. The presence of gamma double prime (i.e., in those specimens from Table III aged at $690 \mathrm{C}$ (1275F) for 16 hours) also results in very high strength levels with a corresponding low level of ductility. The $B$ lend $C$ material shows a bigger ductility reduction than the others (e.g., $B l e n d G)$. This is probably associated with the $M_{6} C$ carbide still present in the material.

The initial gamma double prime that precipitates can only be detected by SEM analysis at magnifications up to about $30,000 \mathrm{X}$ and cannot be resolved optically since the precipitate size is of the order of $200 \AA$. They are disc shaped and they are absent in the denuded zone adjacent to grain boundaries. The hardness and strength increases shown in Table III resulting from the aging cycles are likely caused by a pre-precipitation matrix strain. Longer times and/or higher temperatures would eventualiy result in gamma double prime precipitation, but a better understanding of the hardening mechanism at work in this material in the early stages of precipitation will require transmission electron microscopy.

Some additional work was conducted to determine if delta phase would precipitate in PM 625. In conventional alloy 718 , delta phase is often a desireable microstructural constituent because it promotes notch ductility in creep tests. Figure 8 is a SEM micrograph which shows the precipitation of random delta plates in Blend G material after a heat treatment at 871C (1600F) for 10 hours. The knee of the TTT curve for delta occurs at about 816C (1500F) in about 6 to 8 hours. This is a shift to lower temperature and shorter time for delta phase precipitation than for either conventional a1loy 625 or alloy 718. The exact temperature and time for precipitation of any of the phases in PM 625 will depend on the exact chemistry of the blend in question. 
Table III Room Temperature Tensile Properties of Various PM 625 Blends

\begin{tabular}{|c|c|c|c|c|c|c|c|c|}
\hline Blend & $\begin{array}{l}\text { Solution } \\
\text { Treatment }\end{array}$ & $\begin{array}{c}\text { Aging } \\
\text { Treatment }\end{array}$ & $\mathrm{MPa}^{\mathrm{U}}$ & $\begin{array}{l}\text { ITS } \\
(k s i)\end{array}$ & \multicolumn{2}{|c|}{$\begin{array}{l}0.2 \% \mathrm{YS} \\
\mathrm{MPa} \text { (ksi) }\end{array}$} & $\begin{array}{l}\text { ET } \\
\%\end{array}$ & $\begin{array}{l}\text { RA } \\
\%\end{array}$ \\
\hline A & $1700 \mathrm{~F} / 1 \mathrm{hr} / \mathrm{AC}$ & $1240 \mathrm{~F} / 4 \mathrm{hrs} / \mathrm{AC}$ & 1074 & $(155.8)$ & \multicolumn{2}{|c|}{$674(97.7)$} & 43.0 & 49.9 \\
\hline $\begin{array}{l}\text { C } \\
\text { " } \\
\text { " } \\
\text { " } \\
\text { " } \\
\text { " }\end{array}$ & $\begin{array}{c}1700 \mathrm{~F} / 1 \mathrm{hr} / \mathrm{AC} \\
" \\
" \\
1800 \mathrm{~F} / \mathrm{1}^{1} \mathrm{hr} / \mathrm{AC} \\
"\end{array}$ & $\begin{array}{l}1200 \mathrm{~F} / 4 \mathrm{hrs} / \mathrm{AC} \\
1225 \mathrm{~F} / 4 \mathrm{hrs} / \mathrm{AC} \\
1240 \mathrm{~F} / 4 \mathrm{hrs} / \mathrm{AC} \\
1275 \mathrm{~F} / 8 \mathrm{hrs} / \mathrm{AC} \\
1100 \mathrm{~F} / 4 \mathrm{hrs} / \mathrm{AC} \\
1150 \mathrm{~F} / 4 \mathrm{hrs} / \mathrm{AC} \\
1275 \mathrm{~F} / 16 \mathrm{hrs} / \mathrm{AC}\end{array}$ & $\begin{array}{r}995 \\
1030 \\
1040 \\
1138 \\
944 \\
963 \\
1166\end{array}$ & $\begin{array}{l}(144.4) \\
(149.4) \\
(150.8) \\
(165.1) \\
(137.0) \\
(139.7) \\
(169.1)\end{array}$ & \multicolumn{2}{|c|}{$\begin{array}{ll}579 & (84.0) \\
627 & (91.1) \\
639 & (92.7) \\
747 & (108.4) \\
487 & (70.7) \\
518 & (75.2) \\
822 & (119.2)\end{array}$} & $\begin{array}{l}41.0 \\
39.0 \\
36.0 \\
27.0 \\
46.0 \\
47.0 \\
26.0\end{array}$ & $\begin{array}{l}46.1 \\
40.6 \\
37.5 \\
29.1 \\
43.3 \\
49.1 \\
26.4\end{array}$ \\
\hline $\begin{array}{l}\text { D } \\
" 1 \\
\text { " }\end{array}$ & $\begin{array}{c}1700 \mathrm{~F} / 1 \mathrm{hr} / \mathrm{AC} \\
"\end{array}$ & $\begin{array}{l}1200 \mathrm{~F} / 4 \mathrm{hrs} / \mathrm{AC} \\
1225 \mathrm{~F} / 4 \mathrm{hrs} / \mathrm{AC} \\
1240 \mathrm{~F} / 4 \mathrm{hrs} / \mathrm{AC}\end{array}$ & $\begin{array}{l}1027 \\
1007 \\
1069\end{array}$ & $\begin{array}{l}(148.9) \\
(146.0) \\
(155.0)\end{array}$ & \multicolumn{2}{|c|}{$\begin{array}{ll}602 & (87.3) \\
593 & (86.0) \\
665 & (96.4)\end{array}$} & $\begin{array}{l}37.5 \\
43.0 \\
38.0\end{array}$ & $\begin{array}{l}37.9 \\
47.0 \\
47.8\end{array}$ \\
\hline $\begin{array}{l}\text { E } \\
" 1 \\
" \\
" \\
"\end{array}$ & $\begin{array}{c}1700 \mathrm{~F} / 1 \mathrm{hr} / \mathrm{AC} \\
" \\
1825 \mathrm{~F} / 1 \mathrm{hr} / \mathrm{WQ} \\
" \\
"\end{array}$ & $\begin{array}{l}1200 \mathrm{~F} / 4 \mathrm{hrs} / \mathrm{AC} \\
1225 \mathrm{~F} / 4 \mathrm{hrs} / \mathrm{AC} \\
1240 \mathrm{~F} / 4 \mathrm{hrs} / \mathrm{AC} \\
1100 \mathrm{~F} / 4 \mathrm{hrs} / \mathrm{AC} \\
1150 \mathrm{~F} / 4 \mathrm{hrs} / \mathrm{AC} \\
1200 \mathrm{~F} / 4 \mathrm{hrs} / \mathrm{AC}\end{array}$ & $\begin{array}{r}1023 \\
1020 \\
1077 \\
969 \\
967 \\
1020\end{array}$ & $\begin{array}{l}(148.4) \\
(148.0) \\
(156.2) \\
(140.6) \\
(140.3) \\
(147.9)\end{array}$ & \multicolumn{2}{|c|}{$\begin{array}{ll}622 & (90.2) \\
617 & (89.5) \\
689 & (99.9) \\
520 & (75.4) \\
529 & (76.8) \\
608 & (88.2)\end{array}$} & $\begin{array}{l}41.0 \\
44.0 \\
38.0 \\
44.0 \\
46.0 \\
40.0\end{array}$ & $\begin{array}{l}52.5 \\
48.8 \\
44.8 \\
44.9 \\
53.0 \\
42.8\end{array}$ \\
\hline $\begin{array}{l}F \\
" 1 \\
" \\
" \\
"\end{array}$ & $\begin{array}{c}1700 \mathrm{~F} / 1 \mathrm{hr} / \mathrm{AC} \\
" \\
1825 \mathrm{~F} / \mathrm{l}_{\text {" }} \mathrm{hr} / 0 \mathrm{O} \\
"\end{array}$ & $\begin{array}{l}1200 \mathrm{~F} / 4 \mathrm{hrs} / \mathrm{AC} \\
1225 \mathrm{~F} / 4 \mathrm{hrs} / \mathrm{AC} \\
1240 \mathrm{~F} / 4 \mathrm{hrs} / \mathrm{AC} \\
1100 \mathrm{~F} / 4 \mathrm{hrs} / 0 \mathrm{Q} \\
1150 \mathrm{~F} / 4 \mathrm{hrs} / 0 \mathrm{Q} \\
1150 \mathrm{~F} / 8 \mathrm{hrs} / 0 \mathrm{Q}\end{array}$ & $\begin{array}{r}998 \\
1057 \\
1057 \\
936 \\
984 \\
1019\end{array}$ & $\begin{array}{l}(144.8) \\
(153.3) \\
(153.2) \\
(135.7) \\
(142.7) \\
(147.8)\end{array}$ & \multicolumn{2}{|c|}{$\begin{array}{l}587(85.2) \\
666(96.6) \\
666(96.6) \\
490(71.0) \\
550(79.8) \\
604(87.6)\end{array}$} & $\begin{array}{l}42.0 \\
39.0 \\
38.0 \\
51.0 \\
46.0 \\
44.0\end{array}$ & $\begin{array}{l}50.3 \\
40.7 \\
39.5 \\
56.1 \\
55.7 \\
53.4\end{array}$ \\
\hline $\begin{array}{l}\text { G } \\
" " \\
"\end{array}$ & $\begin{array}{c}1825 \mathrm{~F} / 1 \mathrm{hr} / 0 \mathrm{O} \\
" \\
1800 \mathrm{~F} / 1 \mathrm{hr} / \mathrm{WQ} \\
1600 \mathrm{~F} / 24 \mathrm{hrs} / \mathrm{AC}\end{array}$ & $\begin{array}{l}1150 \mathrm{~F} / 4 \mathrm{hrs} / 0 \mathrm{Q} \\
1150 \mathrm{~F} / 8 \mathrm{hrs} / 00 \\
1200 \mathrm{~F} / 4 \mathrm{hrs} / 00 \\
1275 \mathrm{~F} / 16 \mathrm{hrs} / \mathrm{AC} \\
1200 \mathrm{~F} / 4 \mathrm{hrs} / \mathrm{AC}\end{array}$ & $\begin{array}{r}942 \\
978 \\
973 \\
1152 \\
973\end{array}$ & $\begin{array}{l}(136.7) \\
(141.8) \\
(141.2) \\
(167.1) \\
(141.2)\end{array}$ & \multicolumn{2}{|c|}{$\begin{array}{ll}512 & (74.2) \\
563 & (81.6) \\
563 & (81.6) \\
770 & (111.8) \\
547 & (79.4)\end{array}$} & $\begin{array}{l}48.0 \\
47.0 \\
47.0 \\
35.0 \\
42.0\end{array}$ & $\begin{array}{l}58.7 \\
58.5 \\
59.0 \\
44.8 \\
52.7\end{array}$ \\
\hline & $\begin{array}{l}1100 \mathrm{~F}= \\
1150 \mathrm{~F}= \\
1200 \mathrm{~F}=\end{array}$ & $\begin{array}{l}593 C \\
622 C \\
649 C \\
\end{array}$ & $\begin{array}{l}F= \\
F= \\
F=\end{array}$ & $\begin{array}{l}663 C \\
671 C \\
690 C \\
\end{array}$ & \multicolumn{2}{|c|}{$\begin{array}{l}1700 \mathrm{~F}= \\
1800 \mathrm{~F}= \\
1825 \mathrm{~F}=\end{array}$} & $\begin{array}{l}927 C \\
982 C \\
996 C\end{array}$ & \\
\hline
\end{tabular}


Data in Table III for Blend G material shows that the presence of delta phase (formed during the $871 \mathrm{C}$ [1600F] 24 hour treatment) actually lowers room temperature tensile ductility without changing the strength.

\section{Conclusions}

The microstructural responses in PM 625 are similar to those in conventional alloy 718 except they occur at lower temperatures. This is probably due to increased solubility in the matrix when $\mathrm{Nb}$ is lowered and $\mathrm{Fe}$ is replaced by $\mathrm{Ni}$. The maximum delta phase precipitation occurs at $816 \mathrm{C}$ (1500F) which is at least $38 \mathrm{C}$ (100F) lower than in conventional alloy 625 or alloy 718.

The precipitation of $M_{6} C$ carbides in PM 625 occurs in the range of $927 C$ (1700F) to $1038 \mathrm{C}$ (1900F) and the amount is controlled by the $C$ content. Large amounts of $M_{6} C$ precipitates deplete the matrix of the Mo necessary for good corrosion resistance and also reduce the ductility of the material.

The oxygen content of PM 625 should be minimized as the formation of oxides in improperly processed compacts shows lack of bonding and a significant reduction in tensile ductility.

Additional work is underway to more fully understand the age hardening mechanism in PM 625.

\section{References}

1. J. E. Stulga and B. J. McTiernan, "The Metallurgy and Applications of Rapidly Solidified Alloy 625" (Paper presented at the International Conference on Rapidly Solidified Materials, San Diego, California, 3-5 February 1985), 397.

2. D. Byrd, "Alloy 625 Material Evaluation" (Presented at the Houston Materials Conference, Houston, Texas, 2-4 May 1987).

3. INCO Alloys International, "Inconel alloy 625 Brochure", Huntington, West Virginia, 1985. 